\title{
A framework for evaluating the performance of automated teller machine in banking industries: A queuing model-cum-TOPSIS approach
}

\author{
Christopher Osita Anyaeche ${ }^{a}$ and Desmond Eseoghene Ighravwe ${ }^{b^{*}}$
}

${ }^{a}$ Department of Industrial and Production Engineering, University of Ibadan, Nigeria ${ }^{b}$ Department of Mechanical Engineering, Ladoke Akintola University of Technology, Nigeria \begin{abstract}
A B S T R A C T
The improvement in the provision of banking services to customers enhances bank's performance (profitability and productivity) and the amounts of dividend declared to shareholders as well as bank's competitiveness. One means of fast tracking the service time for bank customers is through the use of self-servicing machines, such as automated teller machine (ATM). Total service cost, expected waiting time in queue, ATM utilization and percentage of customer loss are some of the performance indices that are used to evaluate the service rendered by a bank's ATM. This study proposes a framework for evaluating the performance of ATM by integrating queuing model and Technique for Order of Preference by Similarity to Ideal Solution (TOPSIS) methodology. Applicability of the framework was tested using practical data obtained from four banks in Nigeria. It was observed that the average ATM usage in the study area was less than $50 \%$. The TOPSIS results identified Bank $A$ as the best ranked bank. In addition, the results obtained revealed that banks with two ATM were ranked higher than banks with more than two ATM.
\end{abstract}

\section{Introduction}

The introduction of self-servicing machine known as Automated Teller Machine (ATM) has helped banks in transferring part of the control of cash withdrawal and money transfer to their customers during working and off-working periods. This has improved the interrelationships between bank and their customers. Apart from the ability of banks to provide this banking service through the use of ATM at off-working periods, the provision of ATM at strategic locations has helped in reducing the number of customers in banking halls (Dilijonas et al., 2009; Olatokun \& Igbinedion, 2009; Asabere et al., 2012). Other benefits of ATM are: transfer of funds, payment of bills, display of promotional messages and purchase of Global Systems for Mobile (GSM) communication credits (Asikaogu \& Mbegbu, 2012; Adeoti, 2011). These services are provided using modern Information and Communication Technology (ICT) facilities.

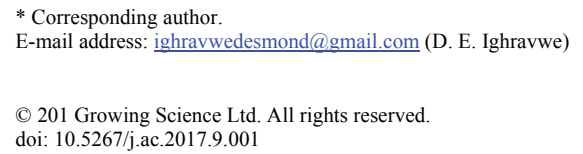


The reduction of customers at banking halls has aided banks in reducing the number of tellers at the banking halls. This has led to the reduction of workforce cost on the part of management, while for customers, the stress of going to banking hall to queue for financial transactions has been reduced considerably (Awodele \& Akanni, 2012). The probability of customers to use the ATM is influenced by the number of withdraw per period and the time spent at the ATM point (Sowunmi et al., 2014). The problem of low service rate of ATM which causes queue at ATM locations is a major determinant of the ATM usage. Surcharges and the features of an ATM do not always affect the use of the ATM significantly (Asikaogu \& Mbegbu, 2012).

The type of ICT (ATM banking, internet banking, credit card transactions and mobile device banking) used by banks affects their service delivery rate, customers' retention and market penetration (Surjadjaja et al., 2003; Asabere et al., 2012). Low service rate affects the number of transaction made at any particular time. This has led to customers wanting to use banks with good ATM services. The low service rate of ATM is usually attributed to network failure, operating system of ATM and interconnectivity problems among banks (Jegede, 2014).

The problem of customers being robbed or their personal identification numbers (PIN) memorised by fraudster when handled carelessly are other challenges of ATM usage. The activities of fraudsters have resulted in financial losses for banks and customers (Awodele, \& Akanni, 2012). These problems are common in areas where the arrival rate of ATM users is high (Olatokun \& Igbinedion, 2009). However, the benefits of using ATM supersede these challenges and its usage continues to spread to areas where it is not currently in use. The satisfaction level which customers derived from ATM usage is affected by the duration spent at queue (Odusina, 2014). The quality of service provided by the ATM serves as a mean of improving bank's competitiveness. It also enhances the relationships between the banks and their customers (McAndrews, 2003). Although, the service rate of teller in banking halls could be more than that of ATM. There is still need to study ATM service rate as it affects customer's waiting time (Laderman, 1990). This will help in determining the actual number of ATM required for a given location. Literature search showed that the application of queuing theory for ATM serve rate analysis is sparse. Also, the analysis of how to rank the performance of ATM among banks appears to under reported in the literature to the best of our knowledge. A study that bridges the above knowledge gaps will improve the analysis of ATM performance for informed decision making. These knowledge gaps motivated the need for this study.

The aim of this study was to rank bank ATM service based on selected performance indices. This was achieved by the proposed a framework which integrates queuing model and Technique for Order of Preference by Similarity to Ideal Solution (TOPSIS) methodology. The queuing model was used to determine the value of bank's ATM performance, while the TOPSIS was used to rank of bank's performance based on the queuing model results.

\section{Methodology}

The following notations are used to present the various performance indices used in the proposed queuing-TOPSIS framework.

$\begin{array}{ll}\lambda_{n} & \text { arrival rate of customers in a system } \\ \mu_{n} & \text { service rate of customer in a system } \\ \text { C } & \text { number of available servers. } \\ P_{n} & \text { steady-state probability of customers in a system } \\ P_{o} & \text { probability of first person in a system } \\ \rho & \text { utilisation factor }\end{array}$




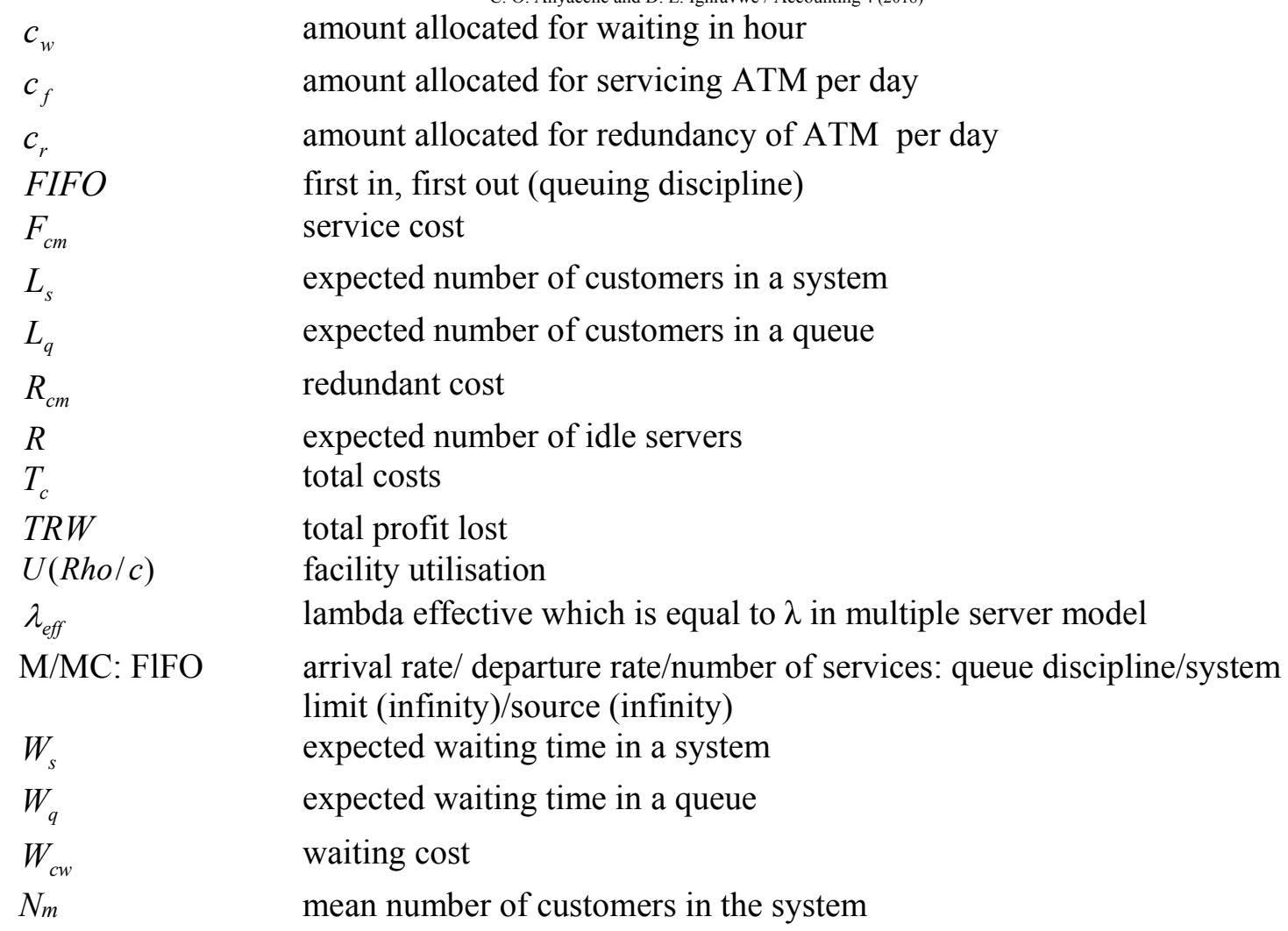

\subsection{Conceptual framework}

The framework that is proposed for ATM performance ranking is based on the evaluation of the ATM performance using queuing model and TOPSIS methodology (Fig. 1).

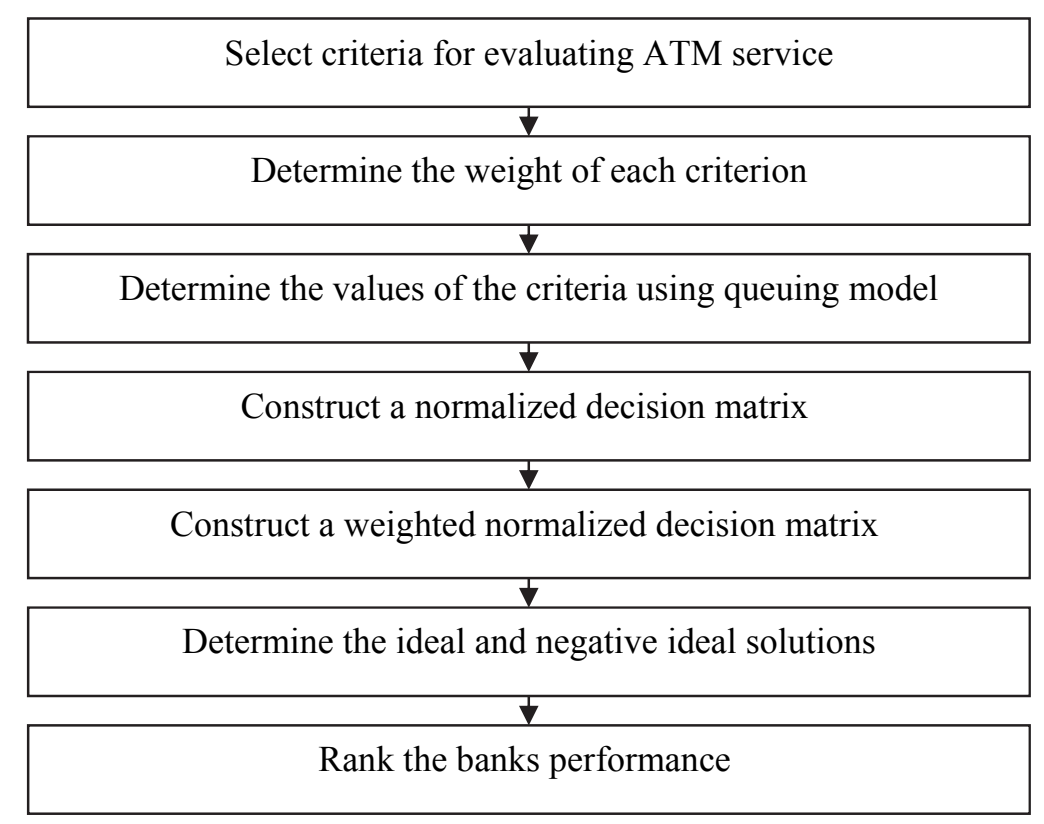

Fig. 1. Conceptual framework for bank's ATM service ranking 


\subsection{Queuing Model for Self-Service Machine}

In self-service machines (ATM), the queuing model assumes multi-server concept in which arrival and service rates follow a Poisson distribution pattern with finite parallel servers. But they have infinite system and source (Taha, 2007). The main inputs to the proposed framework are arrival rate $(\lambda)$ and service rate $(\mu)$ of customers to be served. The outputs are performance indices such as customers waiting time in a queue $\left(\mathrm{W}_{\mathrm{q}}\right)$ and in system $\left(\mathrm{W}_{\mathrm{s}}\right)$, length of a queue $\left(\mathrm{L}_{\mathrm{q}}\right)$ and system $\left(\mathrm{L}_{\mathrm{s}}\right)$, percentage of ATM utilisation and probability of $n$ customers in a system.

The service discipline of the ATM is considered as first-come, first-served (FCFS) which is expressed as a $(\mathrm{M} / \mathrm{M} / \mathrm{c})$ : (FCFS $\infty / \infty)$ model from which the other factors are determined (Taha, 2007). The service rate of $n$ customers in the system is expressed as Eq. (1). The expression for ATM utilisation is given by Eq. (2).

$$
\begin{array}{ll}
\mu_{n}= \begin{cases}n \mu & n<0 \\
c \mu & n \geq c\end{cases} \\
\rho=\frac{\lambda}{\mu}
\end{array}
$$

The steady-state probability of $n$ customers in a system is expressed as Eq. (3), while the sum of all the steady-state probability is given by Eq. (4a) and Eq. (4b).

$$
\begin{aligned}
& P_{n}=\left\{\begin{array}{lll}
\frac{\lambda^{n}}{n ! \mu^{n}} P_{o} & n>c & \\
\frac{\lambda^{n}}{c ! c^{n-c}} P_{o} & n \geq c &
\end{array}\right. \\
& \sum_{n=0}^{\infty} P_{n}=\sum_{n=0}^{c-1} \frac{\rho^{n}}{n !} P_{o} \\
& \sum_{n=0}^{\infty} P_{n}=\sum_{n=0}^{\infty} \frac{\rho^{n}}{c ! C^{n-c}} P_{o}
\end{aligned}
$$

By combining Eq. (4a) and Eq. (4b), and separating variables, the value of $P_{o}$ is expressed as Eq. (5).

$$
\begin{aligned}
& p_{0}=\frac{\sum_{n=0}^{\infty} p_{n}}{\left(\sum_{n=0}^{c-1} \frac{\rho^{n}}{n !}+\sum_{n=c}^{\infty} \frac{\rho^{n}}{c ! c^{n-c}}\right)} \\
& \sum_{n=0}^{\infty} P_{n}=1 \\
& \frac{\rho}{c}<1
\end{aligned}
$$

The sum of all probability is equal to 1 (6). By considering Eq. (7), Eq. (5) is simplified as Eq. (8). 


$$
P_{o}=\left(\sum_{n=0}^{c-1} \frac{\rho^{n}}{n !}+\frac{\rho^{n}}{c !}\left(\frac{1}{1-\rho / c}\right)\right)^{-1}
$$

When $\mathrm{P}_{\mathrm{o}}$ is determined, the expected number of customers in a queue (Lq) is given by Eq. (9). The expected number of customer in a system (Ls) is expressed as Eq. (10), while the expected waiting time of customers in a queue (Wq) is expressed as Eq. (11). Eq. (12) is used to determine the expected waiting time of customers in a system. The percentage utilisation of ATM $(U)$ is given by Eq. (13), while the percentage of customers' loss $(L)$ is expressed as Eq. (14).

$$
\begin{aligned}
& L_{q}=\frac{\rho^{c-1}}{(c-1) !(c-\rho)^{2}} P_{0}, \\
& L_{s}=L_{q}+\rho, \\
& W_{q}=\frac{L_{q}}{\lambda}, \\
& W_{s}=W_{q}+\frac{1}{\mu}, \\
& U=\frac{100 \lambda}{c \mu}, \\
& L=P_{o} \lambda,
\end{aligned}
$$

where $c$ is the number of services.

The service provided by a machine is considered as automatic and the service duration is assumed to be constant. Under these conditions, the service-time distribution has a variance of zero (Blanchard \& Fabrycky, 2010). For the ATM case, the service duration is constant as the number of customers tends towards 30 and above. The mean number of customers in the system is expressed as Eq. (15), while the mean waiting time of ATM is given by Eq. (16).

$$
\begin{aligned}
& n_{m}=\frac{(\lambda / \mu)^{2}}{2(1-(\lambda / \mu))}+\frac{\lambda}{\mu}, \\
& W_{m}=\frac{\lambda / \mu}{2 \mu(1-\lambda / \mu)}+\frac{1}{\mu} .
\end{aligned}
$$

The expected waiting cost per period is the product of waiting per unit per period and the mean number of units in the system (17). The expected facility cost per period is the product of the cost of servicing one unit and the service rate in units per period (18).

$$
\begin{aligned}
& W_{c m}=C_{w}\left(\frac{(\lambda / \mu)^{2}}{2(1-(\lambda / \mu))}+\lambda / \mu\right), \\
& F_{c m}=C_{f} \mu .
\end{aligned}
$$


The expected total system cost per period is the sum of the expected waiting cost per period and the expected facility cost per period (Blanchard \& Fabrycky, 2010) and it is expressed as Eq. (19).

$$
T_{c m}=C_{w}\left(\frac{(\lambda / \mu)^{2}}{2(1-(\lambda / \mu))}+\lambda / \mu\right)+C_{f} \mu .
$$

\subsection{TOPSIS}

The use of single performance index in evaluating the performance of a system tends to bias the judgement of decision makers. This problem becomes more obvious when such performance index computation involves the interaction among several parameters. To address the shortcomings of using single performance index, different multi-criteria modelling approaches have been proposed. Some of these are SAW (Hwang \& Yoon, 1981), PROMETHEE (Brans et al., 1984). TOPSIS (Hwang \& Yoon, 1981, 1994), AHP (Saaty, 1988) and ELECTRE (Roy, 1968, 1991). They seek to generate single values for each option for a course of action. This study selects TOPSIS because of its ease to understand and apply when compared with AHP and ELECTRE. TOPSIS makes use of proportional distance of each option negative idea and ideal solution in generating the rank for each option. The implementation of TOPSIS involves the following procedure (Jadidi et al., 2008; Afkham et al., 2012; Bhutia \& Phipon, 2012):

(i.) Normalisation of the various performance indices in a decision matrix (20)

$$
r_{i j}=\frac{f_{i j}}{\sqrt{\sum_{j=1}^{n} f_{i j}^{2}}} \quad \forall(i, j)
$$

(ii.) Design of a weighted normalized decision matrix by multiplying the normalized decision matrix with weight vectors (21).

$$
V_{i j}=w_{i} r_{i j} \quad \forall(i, j)
$$

where $w_{i}$ is weight assigned to performance index $i$.

(iii.) Determination of the ideal (22) and negative ideal (23) solutions for each of the performance index using information contained in the weighted normalized decision matrix. The value of ideal solution depends on the preferred direction of each performance index.

$$
\begin{aligned}
& A^{+}=\left\{v_{1}^{+}, \cdots, v_{i}^{+}\right\}=\left\{\left(\max v_{i j} \mid i \in I^{\prime}\right),\left(\min _{j} v_{i j} \mid i \in I^{\prime \prime}\right),\right\} \\
& A^{-}=\left\{v_{1}^{-}, \cdots, v_{i}^{-}\right\}=\left\{\left(\min v_{i j} \mid i \in I^{\prime}\right),\left(\max _{j} v_{i j} \mid i \in I^{\prime \prime}\right),\right.
\end{aligned}
$$

where $I^{\prime}$ is the maximum performance index value, and $I^{\prime \prime}$ is the minimum performance index value.

(iv.) Determination of the distance of each bank performance indices from ideal (24) and negative ideal solutions (25). 


$$
\begin{array}{ll}
D_{j}^{+}=\sqrt{\sum_{i=1}^{n}\left(v_{i j}-v_{i}^{+}\right)^{2}} & \forall j \\
D_{j}^{-}=\sqrt{\sum_{i=1}^{n}\left(v_{i j}-v_{i}^{-}\right)^{2}} & \forall j
\end{array}
$$

(v.) Calculation of the rank of each bank using the proportional distance of each bank to its negative ideal solution (26).

$$
R_{j}=\frac{D_{j}^{-}}{D_{j}^{+}+D_{j}^{-}} \forall j
$$

\section{Model Implementation and Discussion of Results}

The proposed framework applicability was demonstrated using a case study drawn from four banks located in Ibadan, Nigeria. The choice of the case study was based on concentration of banks in the study area (Anyaeche et al., 2015). During the study, it was observed that congestion in queuing system takes place during two peak periods. The peak periods were between morning (8.00 a.m. to 11.00 a.m.) and evening (4.00 p.m. to 7.00 p.m.) periods. Data was collected also at night periods. The study hour was between $8.00 \mathrm{a} . \mathrm{m}$. to $11.00 \mathrm{a} . \mathrm{m}$. in the morning, $12.00 \mathrm{p} . \mathrm{m}$. to $3.00 \mathrm{p} . \mathrm{m}$. in the afternoon and 4.00 p.m. to $7.00 \mathrm{p} . \mathrm{m}$. in the evening. Information on the arrival rate, service rate and queue length were collected at $1 \mathrm{hr}$ interval for 30 days. Based on the analysis of the information obtained, different values of $\lambda$ and $\mu$ were determined for different days (Table 1).

Table 1

The arrival and service rates of each of the banks

\begin{tabular}{llllllrll}
\hline & \multicolumn{2}{c}{ Bank A } & \multicolumn{2}{c}{ Bank B } & \multicolumn{3}{c}{ Bank C } & \multicolumn{3}{c}{ Bank D } \\
Days & $\lambda$ & $\mu$ & $\lambda$ & $\mu$ & $\lambda$ & $\mu$ & $\mu$ & 78 \\
\hline 1 & 9 & 10 & 42 & 51 & 40 & 44 & 51 & 73 \\
2 & 7 & 10 & 41 & 53 & 36 & 48 & 54 & 73 \\
3 & 14 & 18 & 42 & 56 & 36 & 47 & 55 & 56 \\
4 & 13 & 13 & 45 & 59 & 39 & 51 & 52 & 68 \\
5 & 14 & 12 & 48 & 57 & 39 & 47 & 59 & 67 \\
6 & 16 & 15 & 44 & 51 & 40 & 48 & 59 \\
7 & 15 & 14 & 49 & 56 & 38 & 47 & 59 & 75 \\
8 & 11 & 13 & 42 & 58 & 38 & 47 & 57 & 76 \\
9 & 8 & 16 & 43 & 51 & 38 & 49 & 61 & 70 \\
10 & 16 & 18 & 50 & 55 & 43 & 45 & 53 & 66 \\
11 & 14 & 11 & 43 & 57 & 40 & 50 & 61 & 72 \\
12 & 11 & 13 & 48 & 54 & 36 & 45 & 52 & 79 \\
13 & 16 & 16 & 48 & 50 & 37 & 46 & 60 & 68 \\
14 & 15 & 18 & 47 & 58 & 35 & 48 & 55 & 74 \\
15 & 8 & 16 & 42 & 59 & 39 & 45 & 58 & 66 \\
16 & 10 & 17 & 44 & 53 & 37 & 46 & 58 & 79 \\
17 & 12 & 17 & 46 & 59 & 42 & 43 & 54 & 76 \\
18 & 12 & 17 & 42 & 52 & 36 & 44 & 61 & 72 \\
19 & 14 & 10 & 46 & 53 & 42 & 50 & 53 & 78 \\
20 & 15 & 15 & 47 & 55 & 36 & 52 & 60 & 68 \\
21 & 10 & 14 & 45 & 51 & 37 & 51 & 55 & 70 \\
22 & 16 & 19 & 42 & 56 & 42 & 47 & 57 & 72 \\
23 & 8 & 16 & 43 & 50 & 43 & 44 & 55 & 65 \\
24 & 7 & 15 & 48 & 55 & 36 & 44 & 51 & 65 \\
25 & 9 & 17 & 47 & 58 & 38 & 51 & 58 & 75 \\
26 & 15 & 14 & 42 & 60 & 38 & 48 & 53 & 73 \\
27 & 13 & 17 & 49 & 51 & 41 & 43 & 54 & 76 \\
28 & 11 & 12 & 46 & 54 & 39 & 47 & 57 & 76 \\
29 & 10 & 18 & 41 & 54 & 38 & 48 & 55 & 68 \\
30 & 9 & 13 & 48 & 53 & 41 & 45 & 54 & 80 \\
\hline
\end{tabular}


Based on the information in Table 1, the average values for Ls, Wq, Ws, loss, utilization and total cost for each of the banks were estimated (Table 2).

Table 2

Decision matrix of the study

\begin{tabular}{lllllll}
\hline Banks & Ls & Wq (hr) & Ws (hr) & Loss & Utilisation (\%) & Total cost (A) \\
\hline A & 1.2278 & 0.0298 & 0.0999 & 0.4245 & 41.3935 & 61528.71 \\
B & 0.8479 & 0.0005 & 0.0189 & 0.3341 & 27.5605 & 228849.10 \\
C & 1.1799 & 0.0090 & 0.0304 & 0.4361 & 41.3238 & 199144.70 \\
D & 0.7744 & $9.6800 \times 10^{-6}$ & 0.0139 & 0.2824 & 19.3467 & 302847.30 \\
\hline
\end{tabular}

By using Eq. (20), the normalized decision matrix for the banks was generated (Table 3). The weighted normalized decision matrix in Table 4 was obtained based on Eq. (21). The weight $\left(w_{i}\right)$ for each of the performance indices was 0.1667 .

Table 3

Normalised decision matrix of the study

\begin{tabular}{lllllll}
\hline Banks & Ls & Wq (hr) & Ws (hr) & loss & Utilisation (\%) & Total cost (N) \\
\hline A & 0.5978 & 0.9574 & 0.9336 & 0.5664 & 0.6133 & 0.1420 \\
B & 0.4128 & 0.0149 & 0.1763 & 0.4458 & 0.4084 & 0.5285 \\
C & 0.5745 & 0.2886 & 0.2837 & 0.5818 & 0.6123 & 0.4600 \\
D & 0.3771 & 0.0003 & 0.1297 & 0.3768 & 0.2867 & 0.6993 \\
\hline
\end{tabular}

\section{Table 4}

Normalised weighted decision matrix of the study

\begin{tabular}{lllllll}
\hline Banks & Ls & Wq (hr) & Ws (hr) & loss & Utilisation (\%) & Total cost (N) \\
\hline A & 0.0997 & 0.1596 & 0.1556 & 0.0944 & 0.1022 & 0.0237 \\
B & 0.0688 & 0.0025 & 0.0294 & 0.0743 & 0.0681 & 0.0881 \\
C & 0.0958 & 0.0481 & 0.0473 & 0.0970 & 0.1021 & 0.0767 \\
D & 0.0629 & $5.1800 \times 10^{-5}$ & 0.0216 & 0.0628 & 0.0478 & 0.1166 \\
\hline
\end{tabular}

Performance indices $L s, W q, W s$, loss and total cost were considered as performance indices whose minimum values were desired. ATM utilization was considered as a performance index whose maximum value was desired. Based on these explanations of the performance indices directions, the ideal and negative solutions for each of the performance indices were calculated (Table 5).

\section{Table 5}

Ideal and negative ideal solutions

\begin{tabular}{lllllll}
\hline Solutions & Ls & Wq (hr) & Ws (hr) & Loss & Utilisation (\%) & Total cost (\#) \\
\hline Ideal & 0.0629 & $5.1824 \times 10^{-5}$ & 0.0216 & 0.0628 & 0.1022 & 0.0237 \\
Negative ideal & 0.0997 & 0.1596 & 0.1556 & 0.0970 & 0.0478 & 0.1167 \\
\hline
\end{tabular}

Based on the information in Tables 4 and 5, the distances of the ideal and negative ideal solutions were estimated (Table 6).

Table 6

Distances of each bank solution from the ideal and negative solutions

\begin{tabular}{lllll}
\hline Solutions & Bank A & Bank B & Bank C & Bank D \\
\hline Ideal & 0.2185 & 0.0340 & 0.0990 & 0.0990 \\
Negative ideal & 0.0981 & 0.0723 & 0.0526 & 0.2185 \\
\hline
\end{tabular}

From the information in Table 6 and Eq. (26), Bank A (0.6901) was ranked first among the four banks based on the six performance indices that were considered. Thus, it is suffice to say that the number of ATM in Bank A should be retained. The second ranked bank was Bank C (0.6533), it has the second highest ATM utilization value and total cost of retaining ATM. Bank B (0.3201) was the third ranked 
bank. Bank D (0.3118) was the last ranked bank. Although, Bank D had the lowest value of the expected waiting time of customers, there is the need for the management to reduce the number of ATM. This will help in improving their ATM utilization value. Based on the results, it can be deduced that banks in the study areas should not use more than three ATM in a location. This suggestion is subject to periodic review using the proposed framework.

\section{Conclusions}

An empirical study on performance ranking of ATM used by banks was presented in this paper. This was achieved using an integrated queuing-TOPSIS framework. The framework considered ATM utilization, percentage of customers' loss, total cost of service and expected length of customers in a queuing system, as well as the expected waiting time of customers in a queuing system and expected waiting time of customers in a queue as performance indices. The results obtained revealed that Bank A was the highest ranked bank, while Bank D was the least ranked bank. The results obtained showed that two banks had ATM utilization values of above 50\%, while the other two banks had ATM utilization values of less than $50 \%$. The average ATM usage in the study area was about $48.02 \%$. Based on these results obtained, banks in the study areas should install one or two ATM at each location. To improve on the utilization of ATM, a study using benefits-cost analysis could be considered as a further study.

\section{References}

Afkham, L., Abdi, A. F., \& Komijan. A. K. (2012). Evaluation of service quality by using fuzzy MCDM: A case study in Iranian health-care centres. Management Science Letters, 2(1), 291-300.

Anyaeche, C. O., Fatuase, L. O., \& Adedeji, P. A. (2015). A performance evaluation model for automated teller machines as self-service machine in selected locations of some banks in Nigeria, Proceedings of Nigerian Institute of Industrial Engineers 2015 International Conference, November 26-28.

Adeoti, J. A. (2011). Automated teller machine (ATM) frauds in Nigeria: The way out. Journal of Social Sciences, 27(1), 53-58.

Asabere, N. Y., Baah, R. O., \& Odediyah, A. A. (2012). Measuring standards and service quality of automated teller machines (ATM) in the banking industry of Ghana. International Journal of Information and Communication Technology Research, 2(2), 216-226.

Asikaogu, C. E., \& Mbegbu, J. I. (2012). Statistical investigation of satisfaction level of automated teller machine (ATM) users in a Nigeria University. AFRREV STECH, 1(3), 178-185.

Awodele, O., \& Akanni, A. (2012). Combating automated teller machine frauds through biometrics. International Journal of Emerging Technology and Advanced Engineering, 2(11), 441-444.

Bhutia, P. W., \& Phipon, R. (2012). Application of AHP and TOPSIS method for supplier selection problem. IOSR Journal of Engineering, 2(10), 43-50.

Blanchard, B. S., \& Fabrycky, W. J. (2010). Systems Engineering and Analysis, $5^{\text {th }}$ ed., Prentice-Hall USA.

Brans, J. P., Mareschal B., \& Vincke PH., (1984). PROMETHEE: A new family of outranking methods in multi-criteria analysis, in: Brans, J.P. (Ed.). Operational Research. North-Holland, Amsterdam, 477-490.

Dilijonas, D., Kriksciuniene, D., Sakalauskas, V., \& Simutis, R. (2009). Sustainability based service quality approach for automated teller machine network. M. Grasserbauer, L. Sakalauskas, E. K. Zavadskas (Eds.), 5th International Vilnius Conference EURO Mini Conference on KnowledgeBased Technologies and OR Methodologies for Strategic Decisions of Sustainable Development (KORSD-2009), 241-246.

Hwang, C., \& Yoon, K. (1981). Multiple Attribute Decision Making: Methods and Applications. New York: Springer-Verlag. 
Jadidi, O., Hong, T. S., Firouzi, F., Yusuff, R. M., \& Zulkifli, N. (2008). TOPSIS and fuzzy multiobjective model integration for supplier selection problem. Journal of Achievement in Materials and Manufacturing Engineering, 31(2), 762-769.

Jegede, C. A. (2014). Effects of automated teller machine on the performance of Nigerian banks. American Journal of Applied Mathematics and Statistics, 2(1), 40-46.

Laderman, E.S. (1990). The public policy implications of state laws pertaining to automated teller machines. Federal Reserve Bank of San Francisco Economic Review, 1, 43-58.

Lai, Y. J., Liu, T. Y., \& Hwang, C. L. (1994). TOPSIS for MODM. European Journal of Operational Research, 76(3), 486-500.

McAndrews, J. (2003). Automated teller machine network pricing a review of the literature. Review of Network Economics, 2(2), 146-158.

Odusina, A. O. (2014). Automated teller machine usage and customers' satisfaction in Nigeria. Elite Research Journal of Accounting and Business Management, 2(3), 43-47.

Olatokun, W. M., \& Igbinedion, L. J. (2009). The adoption of automatic teller machines in Nigeria: An application of the theory of diffusion of innovation. Issues in Informing Science and Information Technology, 6, 373-393.

Roy, B. (1968). Classement et choix en présence de points de vue multiples (la méthode Electre). Revue française d'informatique et de recherche opérationnelle, 2(8), 57-75.

Roy, B. (1991).The Outranking Approach and the Foundation of ELECTRE Methods. Theory and Decision, 31, 49-73.

Saaty, T. L. (1988). The Analytic Hierarchy Process. Mcgraw-Hill, New York.

Sowunmi, F. A., Amoo, Z.O., Olaleye, S.O., \& Salako, M.A. (2014). Effect of Automated Teller Machine (ATM) on demand for money in Isolo local government area of Lagos State, Nigeria. Journal of Applied Business and Economics, 16(3), 171-180.

Surjadjaja, H., Ghosh, S., \& Antony, J. (2003). Determining and assessing the determinants of eservice operations. Managing Service Quality, 13(1), 39-53.

Taha, H.A (2007). Operation Research: An Introduction, 7th Ed. Prentice-Hall, USA.

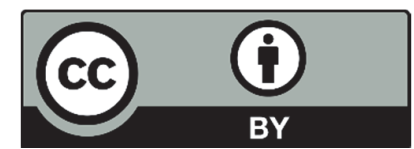

(C) 2017 by the authors; licensee Growing Science, Canada. This is an open access article distributed under the terms and conditions of the Creative Commons Attribution (CC-BY) license (http://creativecommons.org/licenses/by/4.0/). 